\title{
The assessment of evidence associating nonsteroidal anti-inflammatory drugs with complications of peptic ulcerations
}

\author{
MJS LANGMAN, MD
}

\begin{abstract}
A causal relationship is now firmly established between nonsteroidal anti-inflammatory drug (NSAID) use and the occurrence of peptic ulcer complications. In the United Kingdom, rising NSAID use has been matched by rises in ulcer mortality and perforation rates, particularly in older women. It is not likely, however, that drug use accounts for the entire increase. The reasons why some people develop ulcer complications and others do not are poorly understood. It is plausible to propose that other factors, such as history of ulcer or indigestion, current smoking, and alcohol consumption, might raise this risk; however, supportive evidence is lacking. Can J Gastroenterol 1990;4(3):91-94
\end{abstract}

Key Words: NSAIDs, Peptic ulcer complications

\section{Evaluation des données associant anti-inflammatoires non stéroïdiens et complications des ulcérations gastro-duodénales}

RESUME: Une relation causale est désormais fermement établie entre l'usage des anti-inflammatoires non stéroïdiens (AINS) et la survenue des complications de l'ulcère gastro-duodénal. Au Royaume-Uni, il a été démontré que la consommation accrue des AINS correspond à une hausse de la mortalité attribuable aux ulcères et des taux de perforation, surtout chez la femme âgée. Il n'est toutefois pas probable que l'usage de ce médicament explique cette augmentation tout entière. Les raisons pour lesquelles certains sujets souffrent de complications de l'ulcère et d'autres pas restent obscures. Il est plausible que d'autres facteurs, tels l'histoire de l'ulcère ou de l'indigestion, le tabagisme actif et la consommation d'alcool, augmentent ce risque; les preuves concluantes font cependant défaut.
$\mathrm{C}$ LINICALLY, IT IS WELL ACCEPTED that the use of nonsteroidal antiinflammatory drugs (NSAIDs) will predispose to peptic ulcer complications of bleeding and perforation. The strength of evidence supporting this view varies, however, as it derives from a variety of sources, including animal and human experimental studies, clinical reports of suspected adverse responses, retrospective studies with or without controls, and prospective surveillance programs. The value of these findings must therefore be judged by standard criteria which can be employed in assessing any set of evidence bearing upon disease
Department of Medicine, Queen Elizabeth Hospital, Birmingham, United Kingdom

Correspondence and reprints: Dr MJS Langman, Department of Medicine, Queen Elizabeth Hospital, Birmingham B15 2TH, United Kingdom causation regardless of the factors involved. The basic criteria include: consistency of disease occurrence following exposure, strength of association, dose response, timing, logic and accommodation of confounding variables.

\section{DESCRIPTION OF BASIC CRITERIA}

Consistency of disease occurrence following exposure: Confirmation of an association requires the occurrence of disease in individuals exposed with at least reasonable frequency to the etiological factor under consideration. In addition, exposure to this factor should be detected more frequently in individuals with the disease under consideration than in control individuals without it. The possibility that the etiological association is due to the effect of another associated factor (referred to as a 'confounding variable') should always be examined. For example, in assessing the importance of smoking habits, the confounding influence of concurrent alcohol consumption must be considered. Furthermore, it is necessary to consider whether the control group chosen represents a fair comparator. Controls should be chosen to be as similar as possible to the disease group except for being free from the disease in question. This implies similarity in age, sex and other factors, such as social class distribution. 
Strength of association: The strength of an association is typically expressed as the 'odds ratio' or 'relative risk'. These ratios state how many times more likely an individual exposed to a particular factor is to develop a disease than one who is not exposed to the same factor. Although a raised risk shows association, it does not necessarily imply causation; raised risks can also be associated with confounding influences. In general, the higher the risk, the greater are the chances that the relevant factor is causal.

Dose response: In order to measure dose response, the intensity of exposure must be graded. Generally speaking, the greater the intensity of exposure, the greater the risk. A good example of this is cigarette smoking in relation to the occurrence of lung cancer.

Timing: Exposure to the relevant factor should occur at an appropriate time interval. Confounding may often occur because disease occurrence alters habits or behaviour in a way which intensifies exposure to a suspected risk factor. Thus cimetidine or other anti-ulcer drug use commonly occurs in the period immediately preceding gastric cancer diagnosis, but the relationship can be readily explained by drug taking for the relief of dyspepsia caused by the cancer itself.

Logic: A logical basis for an association, though not in itself a prime criterion, provides reassurance and strengthens the belief that a proposed association is likely to be causal. It should be noted, however, that in cases where the underlying cause of disease is not understood, much epidemiological evidence is obtained in an effort to ascertain clues to likely etiological factors. In such circumstances the consistency of findings from one study to another becomes especially important, particularly where methodology differs, for instance from retrospective case control to prospective surveillance.

Confounding: Few environmental influences upon disease occurrence operate without the coincidental appearance of associated factors. These may be non-noxious or, although harmful in themselves, independently operating factors. The importance of the former lies in their ability to confuse the nature of the true noxious influence. For example, marital status can influence disease occurrence through change in habits. The latter can alter risk estimates for the influences under prime consideration. For instance, alcohol and tobacco can independently affect the occurrence of esophageal cancer.

\section{RELATING NSAIDS AND GASTRODUODENAL MUCOSAL DAMAGE}

Consistency of evidence: $A$ large body of evidence now exists with regard to NSAID use and gastroduodenal mucosal damage, deriving from a variety of sources and with varying strength.

Spontaneous adverse reaction reports: NSAIDs have appeared prominently in the spontaneously reported adverse reaction registers of many countries and have been responsible for one-quarter to one-fifth of all such reports in the United Kingdom and the United States (1-3).

These data are difficult to assess. Spontaneous reports represent a biased sample. These biases lead to reporting or, much more frequently, nonreporting, which is poorly understood. Reports, however, are much more likely to be generated for new rather than old drugs. This of itself invalidates comparisons between individual agents which are based upon spontaneous reports and, with NSAID-associated gastrointestinal adverse events, the occurrences are in common for the class. Nevertheless, reports of serious adverse events of ulcer bleeding, perforation, and death have been so frequent that an important clinical problem must be assumed. Complication rates: Little controlled information is available with regard to perforation of ulcers. In the United Kingdom, a higher rate of prior NSAID use was found among patients with perforated ulcers than among inpatient controls in two studies $(4,5)$. One of these studies included a substantial admixture of patients with ulcer bleeding but focused on those who had been operated upon (5). Furthermore, details of the experimental methods indicated that controls were not collected con- temporaneously and were not matched for age. Surveillance studies in the United Kingdom (6) and the United States (7) have suggested that the risks of ulcer perforation may have been exaggerated. The former study, however, may not have included sufficiently large numbers of elderly people to detect ulcer complications, whereas in the latter study, the number of subjects who developed ulcer complications was rather small and the observed data set included many cases with coding errors. The relative risk, although raised at 1.6, had wide confidence intervals, reflecting the small numbers studied, and the even smaller number with NSAID-associated complications.

Bleeding: Many of the data sets for ulcer bleeding are uncontrolled. How ever, data from one study (8), which employed matched community and hospital inpatient controls, suggested that those with ulcer bleeding, both gastric and duodenal, were between two and five times as likely to have been NSAID users as either control. Risks also differed little for aspirin and nonaspirin NSAIDs. Surveillance of Medicaid script recipients in Michigan and Minnesota revealed a raised relative risk (1.5) with a $95 \%$ confidence interval of 1.1 to 1.9 for upper gastrointestinal bleeding from all sources (9). By contrast, no material risk for upper gastrointestinal bleeding was found at Puget Sound, Washington, USA, in individuals aged 65 or less. Of the 301 patients admitted to hospital, 14 had filed a prescription for an NSAID in the previous 90 days; all patients bleeding from duodenal ulcer in the period under review were excluded (10).

Ulcer death: The same raised risk of death from ulcer in NSAID recipients (relative risk 4.7) was found in two North American studies; one from Saskatchewan (11), and the other from Tennessee (12). This risk, however, was limited to those aged 75 and over in the former study.

Strength of association and dose response: The strength of an association is conventionally measured by the relative risk or odds ratio, which states how much more or less likely it is for an 
individual who possesses a particular characteristic to develop a specific condition than for one without such a characteristic. Where NSAID use is concerned, this risk, when raised, has been found to be of the order of two- to fourfold. Such a figure, however, does not measure the absolute risk. This cannot be obtained without either some accompanying measure of the actual risk in the ordinary population or an odds ratio, ie, a measure of the actual risk in NSAID users and the difference compared with the base population. In Michigan and Minnesota (9), two cases of hemorrhage were estimated to occur for every 11,000 individual months of treatment, a figure which corresponds with estimates of risk in the United Kingdom (8,13).

Increased risk, according to intensity or duration of exposure to a suspected etiological agent, usually provides confirmatory evidence of causation. This type of evidence, however, is not available; variation in the anti-inflammatory strength and pharmacokinetic properties of individual drugs makes it impossible to create logical compilations for direct comparisons.

Timing: All available data sets have been collected with consideration given to drug intake in the immediate preceding time period. It is therefore not possible to dissect the information further.

Logic: NSAIDs have been commonly associated with dyspepsia. Furthermore, experimental studies and clinical trials have shown that NSAID treatment is associated with the appearance of upper gastrointestinal lesions, mainly gastric antral in site and varying in degree from hemorrhagic spots to erosions or ulcers (14-17).

What is less clear is the basis for the occurrence of ulcer complications, assuming that NSAID treatment has a causal role. A third or more of NSAID recipients may develop dyspepsia (18), but ulcer complications seem to occur in less than one in 1000. NSAID treatment inhibits platelet function, which could account for the tendency to hemorrhage. It does not, however, explain ulcer perforation.

Clinical experience in the United
Kingdom and elsewhere have suggested that the occurrence of dyspepsia correlates poorly with liability to ulcer complications $(19,20)$. By contrast, in the United States rheumatoid arthritis patients receiving NSAIDs appeared to be at six times the risk of hospital admission due to gastrointestinal disease compared to nonrecipients with rheumatoid arthritis (21). Characteristically, this association held for older individuals who had previous histories of NSAID intolerance. Pharmacologically, it might be expected that adverse events would occur in those with unduly slow NSAID metabolism or those taking drugs with long half-lives. The limited available evidence, however, gives no indication that pharmacokinetic properties can predict symptom occurrence, and clear differences in relative risks between drugs have yet to emerge $(22,23)$.

Confounding: Current clinical evidence suggests that the elderly are particularly prone to develop NSAID. associated complications and may also be the group most prone to peptic ulceration. Most formal studies, therefore, account for confounding by age. Another important factor is confounding by disease indication. There is some reason to believe that patients with rheumatoid arthritis may be more prone to peptic ulceration than expected. However, the bulk of NSAID-associated ulcer complications seem to occur in individuals who do not have rheumatoid arthritis. Disability associated with rheumatoid arthritis has been associated with liability to peptic ulceration, but multivariate analysis has not been used to separate disability from drug treatment (21); indeed, they may not be separable by formal study. The degree of disability associated with osteoarthritis, the most common indication for NSAID treatment, has not been associated with susceptibility to ulcer.

\section{DISCUSSION}

There seems good reason to accept that NSAID treatment is frequently associated with the onset of dyspepsia and that peptic ulceration may ensue. Further complications, however, are rare.
Some clinical studies, but not all, have shown that patients in whom complicated ulceration develops may have had no prior symptoms. The reasons are unclear; thus, we do not know if the complication occurs in a newly developed or an established ulcer. Nevertheless, there seems to be adequate evidence for accepting that NSAID treatment is associated with the development of ulcer complications and that the association is causal.

What remains unclear is why some individuals develop ulcer complications and others do not, and whether there are material differences in gastric and duodenal susceptibility to damage. Experimental studies and short term human investigations in normal volunteers suggest that the gastric antrum may be the prime site of damage (14. 17). Whether investigations in healthy volunteers (who are usually young) can be used to predict the site and pattern of damage in older people with chronic diseases is uncertain. In the United States the broad assumption tends to be made that damage is mainly gastric. Evidence from elsewhere is conflicting. Thus, no difference was found in the risks of gastric and duodenal ulcer bleeding which were equally raised in NSAID takers (8). By contrast, in Australia a raised risk of developing gastric ulcer was detected in one study without a parallel risk for duodenal ulcer (24).

Kurata (25), in reviewing the available United States and United Kingdom studies, noted that differing physician practice study designs and populations which were examined could have contributed to the variable results obtained from one study to another. Another factor may be a difference in underlying trends of ulcer frequency and behaviour. Thus, in the United Kingdom ulcer perforation rates, used as proxy for incidence data, have fallen steeply in men, whereas rates, particularly of duodenal ulcer, have risen in elderly women (13). The reasons for the rise were unclear and could not be ascribed to either smoking habits or changes in NSAID use, although these could have accounted for part of the rise. Despite decreasing 
United States hospitalization and mortality rates over the past 30 years, selfreported ulcer prevalence has risen (25). These trends may be related to a shift to outpatient management using new drugs. Alternatively, United States data show a sex ratio corresponding to the rising rate for women found in the National Health Interview Survey $(25,26)$. Analytical studies suggest a strong correlation in men and women with smoking habits (27). Although the differences in findings between different areas seem irreconcilable in the main, limited agreement exists in suggesting that differences in ulcer frequency between men and women may be disappearing, and that NSAID use

\section{REFERENCES}

1. Griffin JP. Survey of the spontaneous adverse reaction reporting schemes in fifteen countries. Br I Clin Pharmacol 1986;22(Suppl):853-1005

2. Committee on the Safety of Medicine Update. 1. Nonsteroidal anti-inflammatory drugs. Br Med J 1986;292:614.

3. Rossi AC, Hsu JP, Faich GA. Ulcerogenicity of piroxicam and analysis of spontaneously reported data. $\mathrm{Br}$ Med J 1987;294:147-50.

4. Collier DS, Pain JA. Nonsteroidal antiinflammatory drugs and peptic ulcer perforation. Gut 1985;26:359-63.

5. Armstrong CP, Blower JL. Nonsteroidal anti-inflammatory drugs and life threatening complications of peptic ulceration. Gut 1987:28:527-32.

6. Inman WHW. Comparative study of five NSAIDs. PEM News 1985;3:3-13

7. Jick SS, Perera DR, Walker AM, et al. Nonsteroidal anti-inflammatory drugs and hospital admissions for perforated peptic ulcer. Lancet 1987;ii:380-2.

8. Somerville KW, Faulkner G, Langman MJS. Nonsteroidal anti-inflammatory drugs and bleeding peptic ulcer. Lancet 1986;i:462-4.

9. Carson JL, Strom BL, Soper KA, et al. The association of nonsteroidal antiinflammatory drugs with upper gastrointestinal bleeding. Arch Intern Med 1987; 147:85-8.

10. Jick H, Feld AD, Perera DR. Certain nonsteroidal anti-inflammatory drugs and hospitalization for upper gastrointestinal bleeding. Pharmacotherapy 1985:5:280-4.

11. Guess HA, West R, Strand LM, et al. Fatal upper gastrointestinal hemorrhage or perforation among users and non-users of nonsteroidal anti-i can account for a minor progression only, perhaps one-quarter of the observed change.

The basis for individual susceptibility is unclear. Ulcer complications associated with NSAID use seem to be particularly prevalent in the elderly, but NSAID use increases with age. Armstrong and Blower (5) suggested that NSAID users might be at particular risk of dying, but this evidence is difficult to evaluate because cases and controls were not age-matched. In another study in Australia, however, there was no evidence that NSAID use affected the chances of dying with ulcer disease over and above that of developing ulcer complications (28).

nflammatory drugs in Saskatchewan, Canada 1983. J Clin Epidemiol 1988:41:35-45.

12. Griffin MR, Ray WA, Schaffner W. Nonsteroidal anti-inflammatory drug use and death from peptic ulcer in elderly persons. Ann Intern Med 1988;109:359-63.

13. Walt R, Katschinski B, Logan R, et al. Rising frequency of ulcer perforation in elderly people in the United Kingdom. Lancet 1986;1:489-92.

14. Sato H, Guth PH, Grossman MI. Role of food in gastrointestinal ulceration produced by indomethacin in the rat. Gastroenterology 1982;83:210-5.

15. Lanza FL, Royer GL, Nelson RS, et al. The effects of ibuprofen, indomethacin, aspirin, naproxen and placebo on the gastric mucosa of normal volunteers. A gastroscopic and photographic study. Dig Dis Sci 1979;24:823-9.

16. Larkai EN, Smith JL, Lidsky MD, Graham DY. Gastroduodenal mucosa and dyspeptic symptoms in arthritic patients during chronic nonsteroidal anti-inflammatory drug use. Am ] Gastroenterol 1987;82:1153-8.

17. Graham DY, Agrawal N, Roth S. Prevention of NSAID induced gastric ulcer with the synthetic prostaglandin misoprostol. A multicentre doubleblind placebo-controlled trial. Lancet 1988; ii: $1277-80$.

18. Husby G, Holme 1, Rugstad HE, et al. A double-blind multicentre trial of piroxicam and naproxen in osteoarthritis. Clin Rheumatol 1986;5:84-91.

19. Mellem M, Stave R, Myers J, et al. Symptoms in patients with peptic ulcer and haematemesis and/or melaena related to the use of nonsteroidal anti-in-

\section{CONCLUSIONS}

Despite widely varying results of retrospective case control and surveillance studies, the body of evidence generally points to a raised risk of ulcer complications associated with NSAID drug use. The reasons for the discrepancy between the common occurrence of dyspepsia and the much rarer advent of ulcer bleeding or perforation are not understood. Although elderly individuals appear to be at particular risk, they are not frequent users. Furthermore, there is no convincing evidence in the majority who take this drug, nonrheumatoid arthritis patients, which permits the prediction of the individuals at particular risk.

flammatory drugs. Scand ]

Gastroenterol 1985;20:1246-8.

20. Clinch D, Banerjee AK, Ostick G. Absence of abdominal pain in elderly patients with peptic ulcer. Age Ageing 1984;13:120-3.

21. Fries JF, Miller SR, Spitz PW, et al. Towards an epidemiology of gastropathy associated with nonsteroidal anti-inflammatory drug use. Gastroenterology 1989;96:647-55.

22. Rugstad HE, Hundal O, Holme I, et al Piroxicam and naproxen plasma concentrations in patients with osteoarthritis relative to age, sex, efficacy and adverse effects. Clin Rheumatol 1986;5:389-98.

23. Carson JL, Strom BL, Morse LM, et al. The relative gastrointestinal toxicity of the nonsteroidal anti-inflammatory drugs. Arch Intern Med 1987;147:1054-9.

24. Duggan JM, Dobson AJ, Johnson H, et al. Peptic ulcer and nonsteroidal anti-inflammatory agents. Gut 1988;27:929-33.

25. Kurata JH. Ulcer epidemiology: An overview and proposed research framework. Gastroenterology 1989;96:569-80.

26. Kurata JH, Haile BM, Elashoff JD. Sex differences in peptic ulcer disease. Gastroenterology 1985;88:96-100.

27. Kurata JH, Elashoff JD, Nogawa AN, Haile BM. Sex and smoking differences in duodenal ulcer mortality. Am J Public Health 1986;76:700-2.

28. Henry DA, Johnston A, Dobson A, Duggan J. Fatal peptic ulcer complications after the use of nonsteroidal antiinflammatory drugs, aspirin and corticosteroids. Br Med J 1987; 295:1227-9 


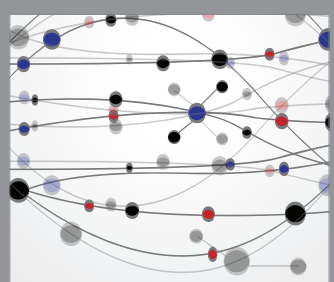

The Scientific World Journal
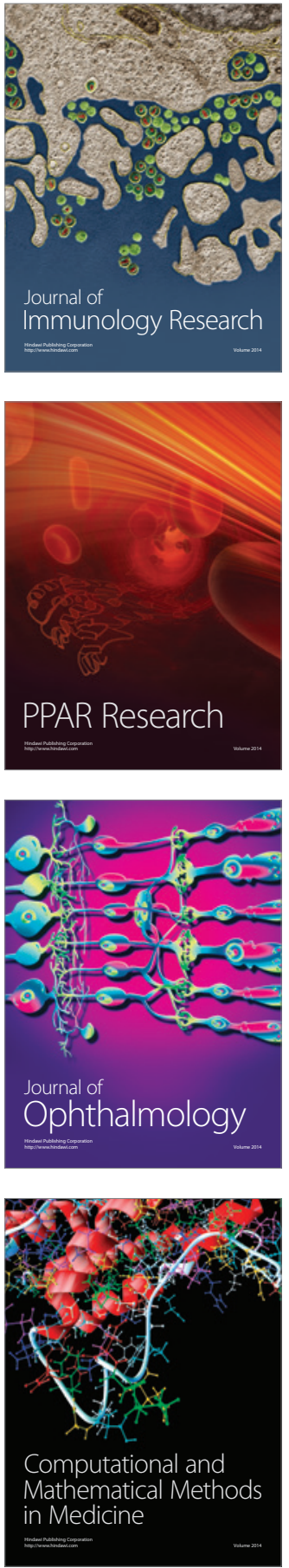

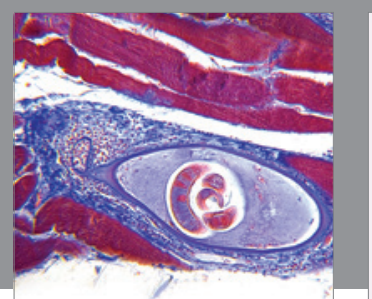

Gastroenterology Research and Practice

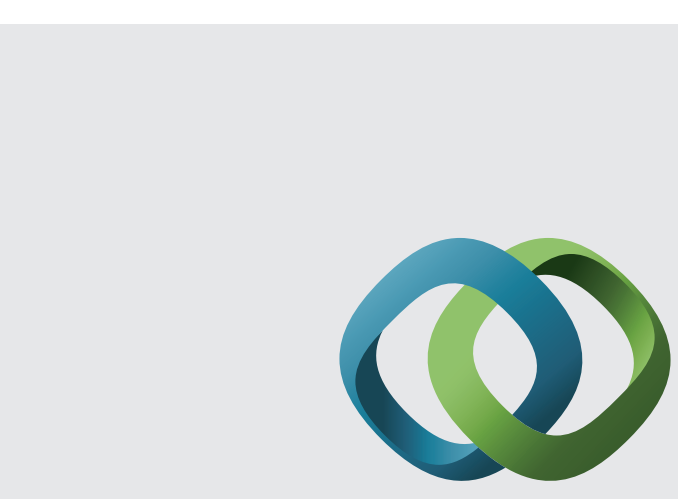

\section{Hindawi}

Submit your manuscripts at

http://www.hindawi.com
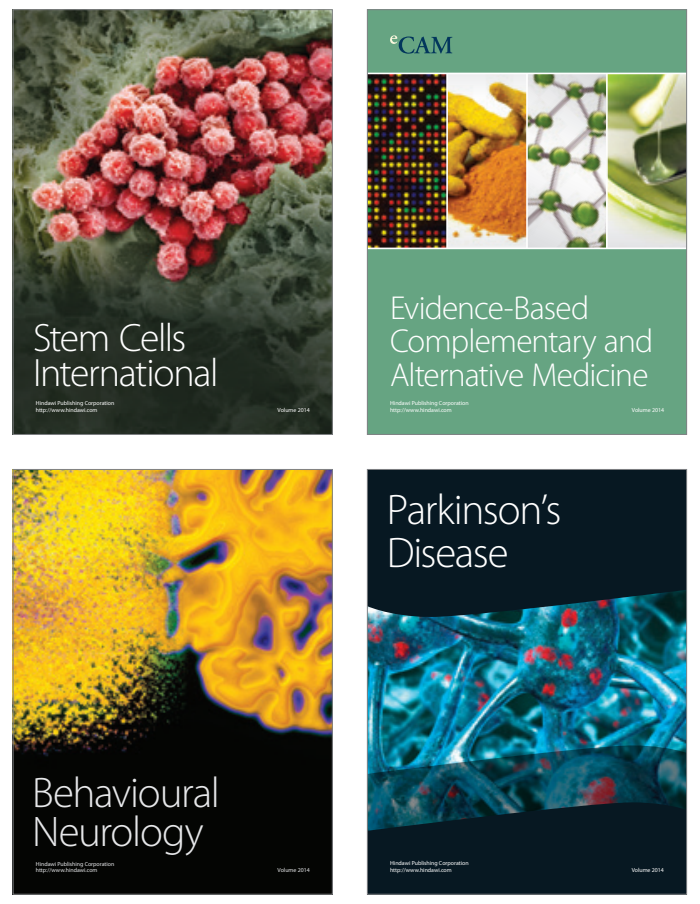
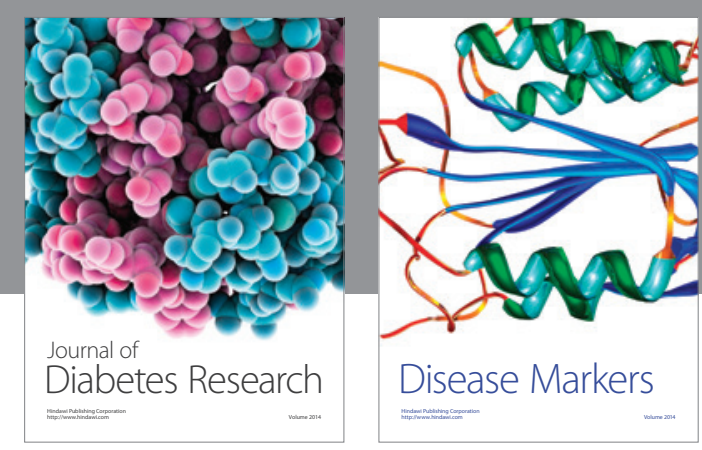

Disease Markers
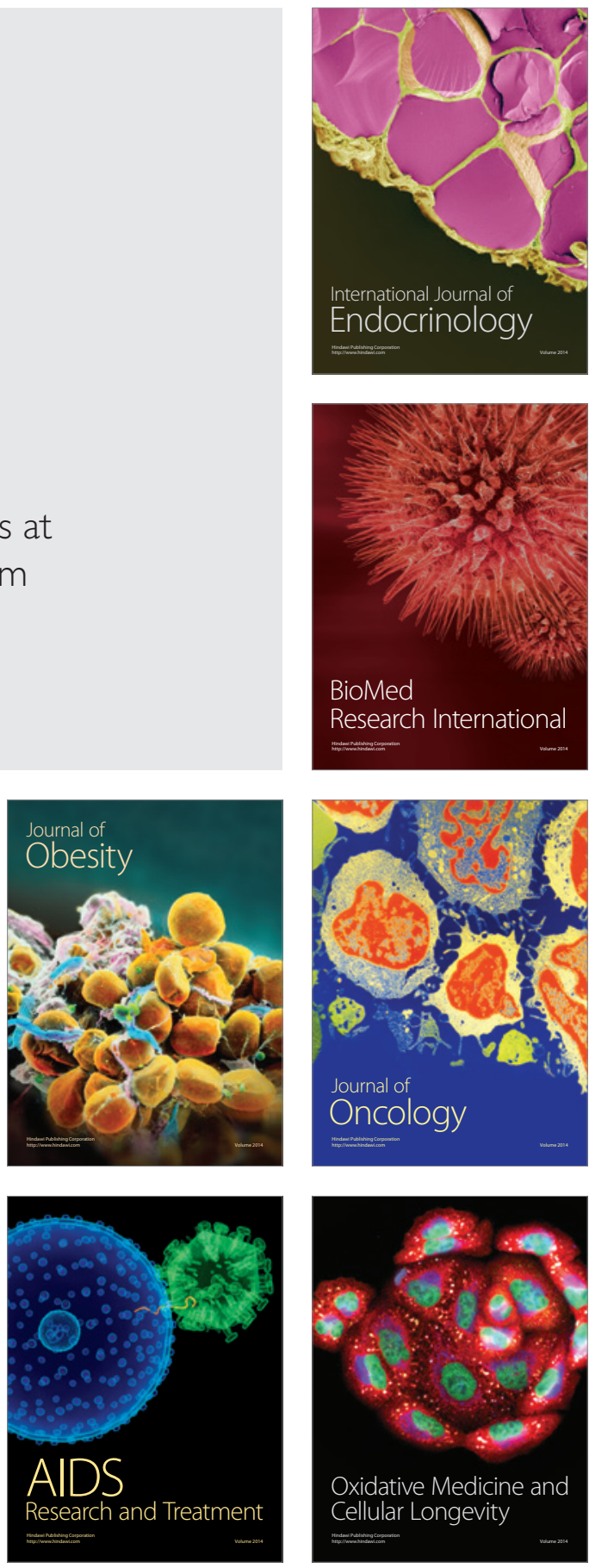